\title{
Mammary Lipid-Rich Carcinoma with Extensive Amyloid Deposition in a Dog
}

\author{
Meina TEI ${ }^{1)}$, Kazuyuki UCHIDA ${ }^{1) *}$, James K. CHAMBERS ${ }^{1)}$, Hiromi HARADA ${ }^{2)}$, Masashi TAKAHASHI ${ }^{2)}$, \\ Ryohei NISHIMURA ${ }^{3)}$, Manabu WATANABE ${ }^{4)}$ and Hiroyuki NAKAYAMA ${ }^{1)}$ \\ 1)Department of Veterinary Pathology, Graduate School of Agricultural and Life Sciences, The University of Tokyo, Tokyo 113-8657, \\ Japan \\ 2) Department of Veterinary Internal Medicine, Graduate School of Agricultural and Life Sciences, The University of Tokyo, Tokyo \\ 113-8657, Japan \\ 3) Department of Veterinary Surgery, Graduate School of Agricultural and Life Sciences, The University of Tokyo, Tokyo 113-8657, Japan \\ 4) Laboratory of Functional Genomics, Department of Medical Genome Sciences, Graduate School of Frontier Sciences, The \\ University of Tokyo, Tokyo 113-8657, Japan
}

(Received 25 October 2011/Accepted 6 January 2012/Published online in J-STAGE 20 January 2012)

ABSTRACT. A 6-year-old female Labrador retriever presented with a mass in the right mammary gland, and swollen right inguinal and axillary lymph nodes. Fine needle aspiration biopsy suggested a malignant lipid-producing tumor, such as liposarcoma. Histopathologically, the neoplasms were solid, lobulated nests of atypical epithelial cells with a large amount of extracellular deposits of amyloid in both mammary gland and lymph nodes. The proliferating cells contained large cytoplasmic vacuoles, positive for oil red-O. These cells were immunopositive for cytokeratin (AE1/AE3) and $\beta$-casein and negative for SMA. The amyloid deposits were immunopositive for $\beta$-casein. These findings suggested that the proliferating cells secreted $\beta$-casein forming amyloid deposits. This is the first report of mammary lipid-rich carcinoma with extensive amyloid deposition derived from $\beta$-casein.

KEY WORDS: amyloid, canine, casein, immunohistochemistry, mammary lipid-rich carcinoma.

doi: 10.1292/jvms.11-0482; J. Vet. Med. Sci. 74(6): 809-811, 2012

Lipid-rich carcinoma is a malignant mammary gland tumor characterized by neoplastic cells with abundant vacuolated cytoplasm containing a large amount of neutral lipid [3]. According to the World Health Organization (WHO) tumor classification system of domestic animals, this type of tumor is extremely rare and classified into special types of mammary tumors, which may be found in younger bitches [4]. There have been several reports of canine, feline and Djungarian hamster cases of the tumor $[2-4,11]$. Human lipid-rich carcinoma is also a rare breast cancer and is classified as lipid-secreting carcinoma, a specific histological type of breast carcinoma according to the 2003 WHO classification [1]. Human lipid-secreting carcinoma is characterized by the morphology of extensive ductal carcinoma, the neoplastic cells of which are abundant in foamy lipid cytoplasm, and by a more aggressive clinical course and a worse prognosis than other types of breast cancer [6].

Localized amyloidosis associated with canine mammary lipid-rich carcinoma has been reported previously and the histochemical and ultrastructural characteristics of the amyloid were described [8].

In the present case, a 6-year-old intact female Labrador retriever presented with a mass $(2 \times 1.3 \times 1.4 \mathrm{~cm})$ in the $3 \mathrm{rd}$ mammary gland and swollen right axillary and inguinal

\footnotetext{
*Correspondence to: Uchida, K., Department of Veterinary Pathology, The University of Tokyo, Tokyo 113-8657, Japan. e-mail: auchidak@mail.ecc.u-tokyo.ac.jp

(C)2012 The Japanese Society of Veterinary Science
}

lymph nodes. Fine needle aspirates from the mass lesions presented aggregates of cells with atypical round nuclei and various amounts of lipid-like vacuoles in the cytoplasm. Although these cells had slight cellular adhesion, a lipid-producing malignant tumor such as liposarcoma was suspected based on the finding of lipid-like vacuoles in the cytoplasm.

The mammary mass and lymph nodes were surgically excised and ovariohysterectomy was also performed. Grossly, the neoplastic mass was grayish white, soft and poorly circumscribed. On the cut surface, poorly defined multiple foci were observed. Normal structures of the mammary gland and lymph nodes were replaced by the lesion.

The excised masses were fixed in 10\% neutral-buffered formalin, embedded in paraffin and sectioned at $2 \mu \mathrm{m}$ for hematoxilin and eosin (HE) staining and immunohistochemical staining and sectioned at $4 \mu \mathrm{m}$ for Alcian blue-periodic acid Schiff (PAS) staining and Congo red staining. After deparaffinization, sections were stained with HE. Histochemical and immunohistochemical stains were used for further characterization of phenotypes of the neoplastic cell population and the nature of extracellular deposits. PAS staining and Congo red staining with and without $5 \%$ potassium permanganate pretreatment were performed using paraffin sections. Oil red-O staining was carried out using formalin-fixed $15 \mu \mathrm{m}$ frozen sections.

Histopathological examinations of the lesions revealed that atypical tumor cells were arranged in a tubuloacinar pattern forming various sizes of nests in both mammary gland and lymph nodes. Individual cells contained a mod- 


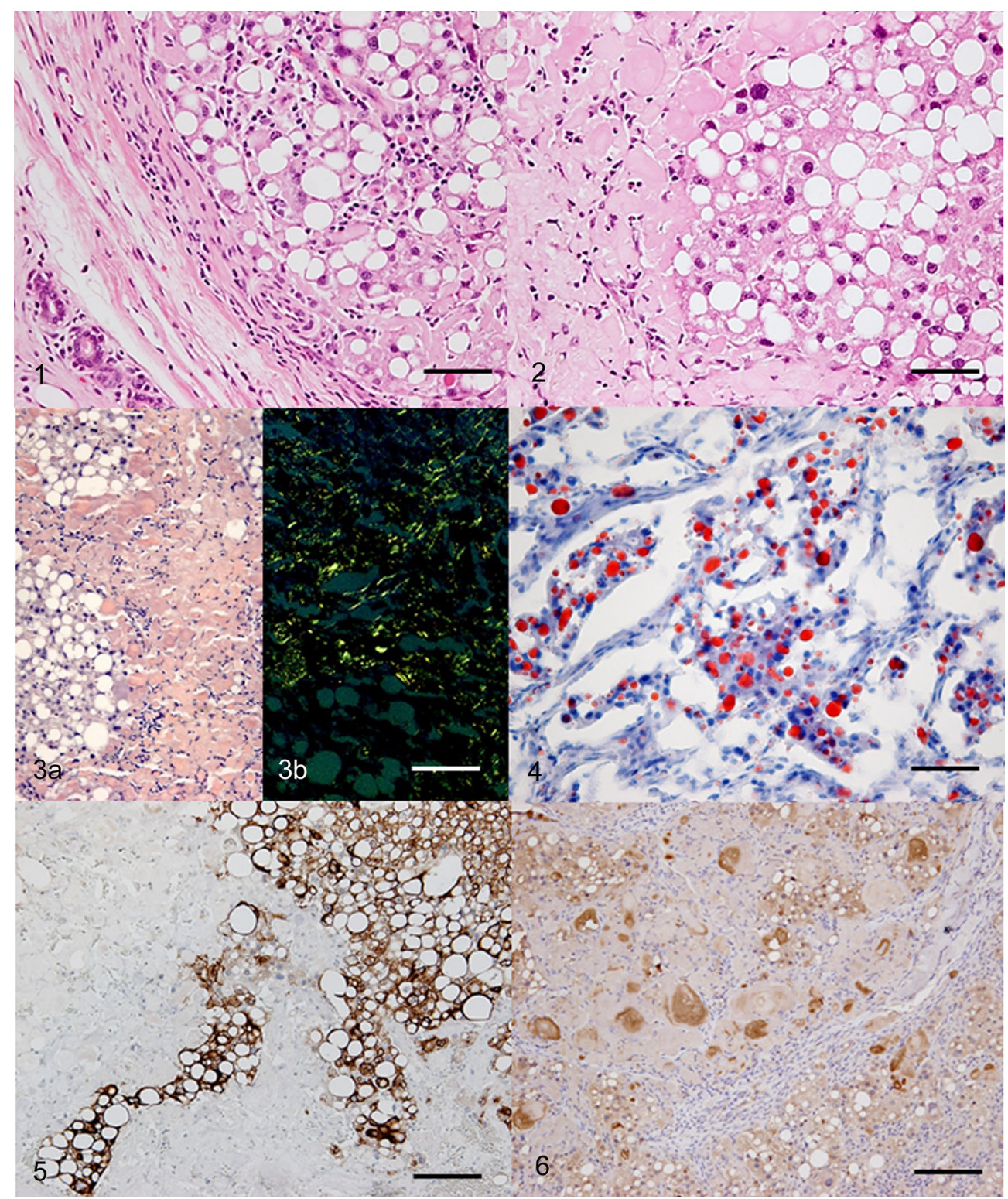

Fig. 1. Mammary gland; dog, The foci of neoplastic cells compressed normal mammary glands. HE. staining. Bar: $50 \mu \mathrm{m}$.

Fig. 2. Mammary gland; dog, Neoplastic cells contained variously sized vacuoles, which compressed the nucleus to the periphery, and a large amount of extracellular amorphous eosinophilic material was seen. HE. staining. Bar: $50 \mu \mathrm{m}$.

Fig. 3. Mammary gland; dog. Extracellular amorphous eosinophilic material was stained with Congo red (a). The materials had green birefringence under polarized light (b). Bar: $100 \mu \mathrm{m}$.

Fig. 4. Mammary gland; dog. Cytoplasmic vacuoles were stained with Oil Red-O. Bar: $100 \mu \mathrm{m}$.

Fig. 5. Mammary gland; dog. Vacuolated neoplastic cells were positive for anti-cytokeratin. Immunohistochemistry, diaminobenzidine chromogen, Mayer hematoxylin counterstain. Bar: $50 \mu \mathrm{m}$.

Fig. 6. Right axillary lymph node; dog. Neoplastic cells and extracellular eosinophilic materials were positive for $\beta$-casein. Immunohistochemistry, diaminobenzidine chromogen, Mayer hematoxylin counterstain. Bar: $100 \mu \mathrm{m}$.

erate to abundant eosinophilic cytoplasm with variablesized, distinct, round and clear vacuoles, which compressed the nucleus to the periphery (Figs. 1 and 2). Large amounts of homogeneous eosinophilic materials were scattered mul- tifocally in the stromal areas of the neoplastic lesions (Fig. 2). The extracellular eosinophilic materials were weakly positive for PAS. These materials were intensely positive for Congo red with and without $5 \%$ potassium permanga- 
nate pretreatment (Fig. 3a). In addition, they had a green birefringence under polarized light (Fig. 3b). Cytoplasmic vacuoles of the neoplastic cells were negative for both PAS and Alcian blue, but strongly positive for oil red-O (Fig. 4). These histochemical profiles confirmed the presence of lipid in the cytoplasmic vacuoles of the neoplastic cells.

Immunohistochemical staining, using anti-human cytokeratin (clone AE1/AE3), anti-vimentin, anti-human smooth muscle actin, anti-human $\kappa$-light chain, anti-human $\lambda$-light chain (all purchased from Dako A/S, Copenhagen, Denmark), anti-human $\beta$-casein and anti-human $\alpha$-lactalbumin (both purchased from Santa Cruz Biotechnology, Santa Cruz, CA, U.S.A.), was performed on paraffin sections using the Dako EnVision system. Sections of canine normal lymph node and mammary gland were used to verify the availability of antibodies used. As antigen retrieval, the deparaffinized sections were autoclaved in citrate buffer $(\mathrm{pH}$ $6.0)$ at $121^{\circ} \mathrm{C}$ for $15 \mathrm{~min}$. As a result, neoplastic cells were positive for cytokeratin and $\beta$-casein (Figs. 5 and 6) and negative for vimentin and SMA. Since neoplastic cells were epithelial origin, liposarcoma was ruled out. The amyloid deposits were immunopositive for $\beta$-casein (Fig. 6), but negative for others. Staining properties of the neoplastic cells and the amyloid were identical between the neoplastic foci of the mammary gland and the lymph nodes. On the basis of these findings, the case was diagnosed as mammary lipid-rich carcinoma with extensive amyloid deposition. The dog was accordingly treated with doxorubicin once a week for 4 weeks after the complete surgical excision of the mass and lymph nodes. Six months after the surgery, the dog was clinically healthy with no signs of local recurrence or metastasis.

Immunohistochemical analysis revealed that the present mammary tumor and its metastatic lesions in the lymph nodes consisted of simple proliferation of lipid-rich glandular epithelial cells without a myoepithelial cell component. Since both neoplastic cells and amyloid deposits were immunopositive for anti- $\beta$-casein, the neoplastic cells might have a prominent ability to secrete the protein, and finally produce amyloid deposits. The presence of $\beta$-caseinderived amyloid in canine lipid-rich carcinoma has never been reported previously.

The canine milk proteins mainly consist of $\alpha-\beta$-, $\kappa$-casein and $\beta$-lactoglobulin, which are produced by mammary epithelial cells [5]. The cells produce casein proteins even when animals are not in a lactating condition. The amphiphilic nature of $\beta$-casein is responsible for easily changing the protein structure and/or conformation between hydrophobic and hydrophilic phases [9]. It is also reported that in vitro homocysteinylation of casein lysyl residues induces an increase in beta-sheet content, which in some cases may be characteristic of amyloid-like transformation [7]. In the present case, it is considered that neoplastic cells produced an excessive amount of $\beta$-casein and the local environment caused a conformational change and an increase in betasheet content in casein, and finally those casein proteins aggregated as amyloid.

Taniyama et al. reported a case of amyloid-producing mammary adenocarcinoma characterized by a papillary, tubular and partly solid pattern of proliferation [8]. They indicated that amyloid consisted of $\alpha$-casein. Amyloid deposits were not observed in metastatic lesions. In contrast, amyloid in the present case contained $\beta$-casein, and amyloid deposits were also observed in the metastatic lesions of the lymph nodes. Together with the previous and present studies, amyloid proteins in canine mammary gland tumors are casein proteins.

There are two theories regarding the origin of lipids in lipid-rich carcinoma: neoplastic cells produce and secrete them, or they are the result of degenerative change [10]. In this case, since lipid droplets existed in the cytoplasm of neoplastic cells uniformly and were found also in the metastatic lymph nodes, these lipids are not likely to be the result of degenerative change, but the neoplastic cells themselves might have produced them.

\section{REFERENCES}

1. Deviliee, P. and Tavassoli, F. A. 2003. World Health Organization: Tumour of the Breast and Female Genital Organs, 1st ed., Oxford University Press, Oxford.

2. Espinosa de los Monteros, A., Hellmen, E., Ramirez, G. A., Herraez, P., Rodriguez, F., Ordas, J., Millan, Y., Lara, A. and de las Mulas, J. M. 2003. Lipid-rich carcinomas of the mammary gland in seven dogs: Clinicopathologic and immunohistochemical features. Vet. Pathol. 40: 718-723. [Medline] [CrossRef]

3. Goldschmidt, M., Pena, L., Rasotto, R. and Zappulli, V. 2011. Classification and grading of canine mammary tumors. Vet. Pathol. 48: 117-131. [Medline] [CrossRef]

4. Kamstock, D. A., Fredrickson, R. and Ehrhart, E. J. 2005. Lipid-rich carcinoma of the mammary gland in a cat. Vet. Pathol. 42: 360-362. [Medline] [CrossRef]

5. Meisel, H. 1997. Biochemical properties of regulatory peptides derived from milk proteins. Biopolymers 43: 119-128. [Medline] [CrossRef]

6. Ramos, C. V. and Taylor, H. B. 1974. Lipid-rich carcinoma of breast-clinicopathologic analysis of 13 examples. Cancer 33: 812-819. [Medline] [CrossRef]

7. Stroylova, Y. Y., Zimny, J., Yousefi, R., Chobert, J. M., Jakubowski, H., Muronetz, V. I. and Haertle, T. 2011. Aggregation and structural changes of alpha(S1)-, beta- and kappacaseins induced by homocysteinylation. Biochim. Biophys. Acta 1814: 1234-1245. [Medline]

8. Taniyama, H., Kitamura, A., Kagawa, Y., Hirayama, K., Yoshino, T. and Kamiya, S. 2000. Localized amyloidosis in canine mammary tumors. Vet. Pathol. 37: 104-107. [Medline] [CrossRef]

9. Vessely, C. R., Carpenter, J. F. and Schwartz, D. K. 2005. Calcium-induced changes to the molecular conformation and aggregate structure of beta-casein at the air-water interface. Biomacromolecules 6: 3334-3344. [Medline] [CrossRef]

10. Wrba, F., Ellinger, A., Reiner, G., Spona, J. and Holzner, J. H. 1988. Ultrastructural and immunohistochemical characteristics of lipid-rich carcinoma of the breast. Virchows Arch. A Pathol. Anat. Histopathol. 413: 381-385. [Medline] [CrossRef]

11. Yoshimura, H., Kimura, N., Nakahira, R., Michishita, M., Ohkusu-Tsukada, K. and Takahashi, K. 2010. Lipid-rich carcinoma in the mammary gland of a Djungarian hamster (Phodopus sungorus). J. Vet. Diagn. Invest. 22: 305-309. [Medline] [CrossRef] 